\title{
Predictors of delayed breast reconstruction in the Netherlands: a 5-year follow-up study in stage I-III breast cancer patients
}

\author{
L. S. E. van Egdom ${ }^{1,5}$ - K. M. de Ligt $^{2} \cdot$ L. de Munck ${ }^{3} \cdot$ L. B. Koppert ${ }^{1} \cdot$ M. A. M. Mureau ${ }^{5} \cdot$ H. A. Rakhorst ${ }^{6}$. \\ S. Siesling ${ }^{3,4}$
}

Received: 14 August 2021 / Accepted: 31 October 2021 / Published online: 15 November 2021

(c) The Author(s) 2021

\begin{abstract}
Purpose Delayed breast reconstruction (DBR) is a valid option for postmastectomy breast cancer patients who have a desire for breast reconstruction but are not considered suitable for immediate breast reconstruction (IBR). The objective of this study was to investigate the clinical practice and predictors of the use of DBR in the Netherlands.

Methods Stage I-III breast cancer patients diagnosed from January to March 2012 and treated with mastectomy were selected from the Netherlands Cancer Registry. Routinely collected patient, tumor, treatment and hospital characteristics were complemented with data about DBR up to 2018. Multivariable logistic regression analyses were performed to identify factors independently associated with postmastectomy DBR. Factors associated with time to DBR were identified through Cox regression analyses.

Results Of all patients who underwent mastectomy $(n=1,415), 10.2 \%$ underwent DBR. DBR patients more often received autologous reconstruction compared to IBR patients $(37.5 \%$ vs $6.2 \%, p<0.001)$. Age below 50 years (age $<35$ OR 15.55 , age 35-49 OR 4.18) and neoadjuvant and adjuvant chemotherapy (OR 2.59 and OR 2.83, respectively) were significantly associated with DBR. Mean time to DBR was 2.4 years [range 1-6 years]. Time to DBR was significantly associated with age $<35$ years (HR 2.22), and a high hospital volume (HR 1.87).

Discussion The use of DBR after mastectomy could not be fully explained by age below 50 years, chemotherapy, and hospital volume. Treatment with radiotherapy and adjuvant chemotherapy increased time to DBR. More information about patient preferences is needed to understand the use and timing of reconstruction.
\end{abstract}

Key words Breast cancer $\cdot$ Breast reconstruction $\cdot$ Delayed breast reconstruction $\cdot$ Cancer registry

L. S. E. van Egdom

1.vanegdom@erasmusmc.nl

1 Department of Surgical Oncology, Erasmus MC Cancer Institute, University Medical Center, Rotterdam, The Netherlands

2 Department of Psychosocial Research, Division of Psychosocial Research and Epidemiology, The Netherlands Cancer Institute, Amsterdam, The Netherlands

3 Department of Research and Development, Comprehensive Cancer Organisation (IKNL), Utrecht, The Netherlands

4 Department of Health Technology and Services Research, Technical Medical Centre, University of Twente, Enschede, The Netherlands

5 Department of Plastic and Reconstructive Surgery, Erasmus MC Cancer Institute, University Medical Center, P.O. 2040, 3000 CA Rotterdam, the Netherlands

6 Department of Plastic and Reconstructive Surgery, Medisch Spectrum Twente, Enschede, The Netherlands

\begin{abstract}
Abbreviations
DBR Delayed breast reconstruction

IBR Immediate breast reconstruction

BCT Breast conserving therapy

NCR Netherlands Cancer Registry

MDT Multidisciplinary team meeting
\end{abstract}

\section{Introduction}

In breast cancer treatment, decisions about surgery are part of a continuum of treatment decisions rather than stand-alone decisions. Although breast-conserving therapy (BCT, breast conserving surgery followed by radiotherapy) has become the central component of surgical breast cancer treatment [1], there is still a considerable proportion of patients who undergo mastectomy [2, 3]. Unfortunately, mastectomy is associated with negative effects on body image and psychosocial well-being 
[4-6]. Postmastectomy breast reconstruction is considered an important treatment modality in breast cancer care, as it not only restores the breast contour but also provides psychological, psychosocial and functional improvement, including body image and sexuality [5-9]. Patients treated with mastectomy may opt for breast reconstruction, which is either performed during mastectomy as an immediate breast reconstruction (IBR) or as delayed breast reconstruction (DBR) at any given point in time following mastectomy [10].

Multiple factors may affect the timing of breast reconstruction, including both tumor and treatment characteristics as clinical cancer stage, tumor size and localization, comorbidity, smoking, as well as socioeconomic status and individual patient's and surgeon's preferences [10-13]. While IBR is not absolutely contraindicated in patients who need to undergo radiotherapy, in the Netherlands DBR is generally preferred for patients with a high risk of postmastectomy radiotherapy, specifically in patients with stage II or III breast cancer [10]. Reasons are that radiotherapy following IBR may not only increase the chance of implant loss, reconstruction failure, or poorer aesthetic outcomes [14, 15], but that IBR may also negatively affect the quality of radiotherapy, specifically if tissue expanders with integrated valves are used [16-18]. Finally, it has been shown that differences exist between Dutch hospitals in organization of breast cancer care, which affects the use of IBR [19].

From a patient perspective, common reasons or preferences for choosing DBR over IBR may range from a preference to focus on oncological treatment first $[20,21]$ to the unavailability of the desired technique in the facility of breast cancer treatment [22]. Also, patients may feel it is unimportant, unnecessary, nor urgent [20], or they choose to undergo limited surgery as the first procedure [21]. Ultimately, decisions regarding DBR may be relevant from pre-treatment up to years after breast cancer surgery [23].

Trends in IBR have been evaluated extensively, both nationally [24, 25] and internationally [2, 26, 27]. Compared to IBR, where data can be easily studied as IBR is linked to the mastectomy performed, proper collection of DBR-data is more challenging since DBR can be performed years after mastectomy. Consequently, reliable information regarding the current clinical practice of DBR from a national perspective is lacking. Therefore, the objective of the present study was to investigate the clinical practice of the use of DBR in stage I-III breast cancer patients in the Netherlands and the factors predicting its use.

\section{Methods}

\section{Study population}

As DBR may remain relevant years after breast cancer surgery [23], we selected breast cancer patients diagnosed from January to March 2012 from the Netherlands Cancer Registry (NCR) for our nationwide population-based study. Patients with stage I-III disease, treated with a mastectomy, were included. The NCR records data for all newly diagnosed malignancies in the Netherlands since 1989 and incorporates data on patient, tumor and treatment characteristics. Data about breast reconstruction are only routinely collected for IBR; therefore, information regarding DBR was manually and retrospectively retrieved for our cohort. Patients' electronic health records were checked in 2018, leading to a follow-up period of about five years after diagnosis.

Tumor stage was classified according to the AJCC TNM Classification for Breast Cancer (7th Edition). Topography, morphology, and grade were coded according to the International Classification of Diseases for Oncology, using tumor, node, and metastasis classification system (ICD-O, 3rd edition). Data about recurrent disease was available up to 5 years after diagnosis.

This study was approved by the Privacy Review Board of the NCR.

\section{Construction of variables}

DBR was defined as any reconstruction performed at any other date after mastectomy. To ensure a complete overview, both patients treated with mastectomy only and IBR (defined as any reconstruction on the same date as the mastectomy) were considered as reference group.

Hospitals were grouped according to hospital of oncologic surgery and hospital of reconstruction. The surgical volume of a hospital was defined as the annual number of breast cancer patients in 2012, divided into low-volume $<175(n=51)$, mid-range volume 175-245 $(n=29)$, and high-volume $>245(n=19)$. Hospitals were categorized as either academic hospitals (including cancer centers, $n=8$ ), teaching hospitals $(n=44)$ and general hospitals $(n=51)$. Both academic and teaching hospitals provide medical training to surgical residents. Plastic surgery training is provided in a more limited number of specific hospitals.

\section{Statistical analyses}

Patient, tumor, treatment and hospital characteristics were summarized per treatment group and compared using Pearson Chi-square tests (two-sided). Multivariable logistic 
regression analyses were used to determine factors that were independently associated with use of breast reconstruction in contrast to mastectomy alone, controlled for patient, tumor, and treatment characteristics. In addition, to determine factors predicting DBR, a Cox regression analysis was performed that took the time between mastectomy and DBR into account and was also controlled for patient, tumor, and treatment characteristics. Included variables which were selected based on literature $[10,11]$ were: age at time of surgery, clinical tumor and nodal stage, morphology, differentiation grade, chemotherapy, radiotherapy, hospital type, and hospital volume. Conditions of proportionality were analyzed graphically. In multivariable analyses, $\mathrm{P}$-values $<0.05$ were considered as statistically significant. All analysis was performed using STATA (version 14) [28].

\section{Sample size}

To enable regression analyses, Harris' rule of thumb (1985) prescribes a minimum of ten participants per predictor variable in equations including six or more variables [29]. We expected to include 10-15 independent variables in our multivariable regression, requiring a minimum of $150 \mathrm{DBR}$ patients. In a similar cohort study performed in Denmark, that has an identical nationwide cancer registry, $10.1 \%$ of women received DBR in the years following diagnosis (1999-2006, follow-up to 2009) [30]. By including 1500 patients treated with mastectomy, about a quarter of annually newly diagnosed breast cancer patients treated with mastectomy in the Netherlands, we expected to include enough DBR patients. In 2012, quarterly rates of mastectomy and IBR were constant, suggesting generalizability of DBR-rates over a similar period.

\section{Results}

\section{Patient characteristics}

Of all patients diagnosed with stage I-III breast cancer between January and March 2012, 36\% of patients $(n=1,415)$ had been surgically treated with mastectomy (Table 1). Of these patients, 144 (10.2\%) patients received DBR.

Breast cancer patients with DBR significantly differed from patients with IBR or mastectomy alone. DBR patients had a significantly lower mean age $(p<0.001)$ and were significantly more often diagnosed with a higher clinical stage (stage III: $11.8 \%$; T2-stage: $40.3 \%$ or T3-stage: $13.2 \%$ ) and nodal involvement $(57.6 \%$; $<0.05)$. Statistically significant differences were found between all groups for treatment characteristics, including radiotherapy and chemotherapy
( $p<0.001)$, as well as for hospital type $(p<0.001)$ and hospital volume $(p<0.006$, Table 1).

Figure. 1 shows a flowchart of the treatment characteristics for all breast reconstruction patients following mastectomy. Most patients who had undergone breast reconstruction (either IBR or DBR) were not treated with adjuvant radiotherapy.

\section{Factors associated with the use of DBR}

DBR patients significantly more often received mastectomy at general hospitals compared to IBR patients $(41.7 \%$ versus $28.9 \%$, respectively, $p<0.001)$. Implant-based DBR was performed most frequently $(n=70,48.6 \%)$, followed by autologous DBR ( $n=54,37.5 \%$; Table 2$)$. However, autologous reconstructions were performed significantly more often in DBR patients than in IBR patients $(6.2 \%)$, where implant-based reconstructions were leading $(82.1 \%)$.

A multivariable logistic regression analysis for factors relate to any breast reconstruction (including both DBR and IBR) in contrast to mastectomy alone was performed. The use of BR was significantly and positively associated with age $<35$ years (OR 14.74, CI $7.42-29.26, p<0.001$ ), age 35-49 (OR 4.33, CI 3.18-5.89, $p<0.001$ ), receiving chemotherapy (either neoadjuvant (OR 2.25, CI 1.21-4.20, $\mathrm{p}=0.011)$ or adjuvant (OR 1.62, CI 1.12-2.36, $p=0.011)$ ), and treatment in an academic hospital (OR 1.85, CI 1.11$3.09, p=0.018$ ) or in a hospital of higher volume (middle volume: OR 1.64, CI $1.12-2.42, p=0.010$; high volume: OR 2.42 , CI $1.59-3.69, p<0.001)$. Significantly negatively associated with the use of BR were age $75+($ OR $0.06, C I$ $0.02-0.20, p<0.001$ ), positive lymph node status (OR 0.54 , CI $0.36-0.79, p=0.002)$ or unknown lymph node status (OR 0.17, CI $0.04-0.69, p=0.014$ ), radiotherapy (OR 0.03, CI $0.02-0.04, p<0.001)$, and treatment in a teaching hospital (OR 0.68, CI $0.47-0.99, p=0.046$ ) (Table 3).

As part of a sensitivity analysis, a multivariable logistic regression analysis was performed to determine factors that were independently associated with use of DBR in contrast to mastectomy alone. For DBR specifically, only age $<35$ years (OR 15.55, CI 8.37-28.93, $p<0.001$ ), age 35-49 (OR 4.18, CI 2.84-6.17, $p<0.001$ ), and receiving neoadjuvant chemotherapy (OR 2.59, CI 1.39-4.84, $p<0.001$ ) or adjuvant chemotherapy (OR 2.83, CI $1.75-4.56, p<0.001)$ were significantly and positively associated (data not shown)."

\section{Factors associated with the time between mastectomy and DBR}

Mean time to DBR was 710 days (Table 1). In Fig. 2, time to DBR was categorized by TNM-staging. With an increasing tumor stage, DBR was performed later in 
Table 1 Patient, tumor, treatment, and hospital characteristics for patients treated with mastectomy $(\mathrm{n}=1,415)$, diagnosed between January and March 2012 (n,\%)

\begin{tabular}{|c|c|c|c|c|c|c|c|c|}
\hline & & $\operatorname{DBR}(n=144)$ & $\%$ & $\operatorname{IBR}(n=194)$ & $\%$ & MAS $(n=1077)$ & $\%$ & $p^{*}$ \\
\hline \multicolumn{9}{|l|}{ Patient characteristics } \\
\hline \multirow{5}{*}{$\begin{array}{l}\text { Age in years } \\
\text { (at diagnosis) }\end{array}$} & $<35$ & 22 & $15.3 \%$ & 19 & $9.8 \%$ & 18 & $1.7 \%$ & \multirow[t]{5}{*}{$<0.001$} \\
\hline & $35-49$ & 73 & $50.7 \%$ & 73 & $37.6 \%$ & 169 & $15.7 \%$ & \\
\hline & $50-75$ & 49 & $34.0 \%$ & 99 & $51.0 \%$ & 609 & $56.5 \%$ & \\
\hline & $75+$ & 0 & $0.0 \%$ & 3 & $1.5 \%$ & 281 & $26.1 \%$ & \\
\hline & Mean (range) & 47.4 & $25.1-74.9$ & 51.1 & $26.7-78$. & 64.5 & $26.3-96.5$ & \\
\hline \multicolumn{9}{|l|}{ Tumor characteristics } \\
\hline \multirow[t]{4}{*}{ Stage (clinical) } & I & 43 & $29.9 \%$ & 93 & $47.9 \%$ & 336 & $31.2 \%$ & \multirow[t]{4}{*}{$<0.001$} \\
\hline & II & 78 & $54.2 \%$ & 81 & $41.8 \%$ & 585 & $54.3 \%$ & \\
\hline & III & 17 & $11.8 \%$ & 5 & $2.6 \%$ & 112 & $10.4 \%$ & \\
\hline & Unknown & 6 & $4.2 \%$ & 15 & $7.7 \%$ & 44 & $4.1 \%$ & \\
\hline \multirow[t]{6}{*}{ Clinical tumor size (cT) } & 0/IS & 0 & $0.0 \%$ & 2 & $1.0 \%$ & 2 & $0.2 \%$ & \multirow[t]{6}{*}{$<0.001$} \\
\hline & $\mathrm{cT} 1$ & 58 & $40.3 \%$ & 99 & $51.0 \%$ & 401 & $37.2 \%$ & \\
\hline & $\mathrm{cT} 2$ & 58 & $40.3 \%$ & 69 & $35.6 \%$ & 473 & $43.9 \%$ & \\
\hline & cT3 & 19 & $13.2 \%$ & 10 & $5.2 \%$ & 98 & $9.1 \%$ & \\
\hline & $\mathrm{cT} 4$ & 2 & $1.4 \%$ & 0 & $0.0 \%$ & 55 & $5.1 \%$ & \\
\hline & Missing & 7 & $4.9 \%$ & 14 & $7.2 \%$ & 48 & $4.5 \%$ & \\
\hline \multirow[t]{4}{*}{ Grade } & Grade I & 15 & $10.4 \%$ & 38 & $19.6 \%$ & 145 & $13.5 \%$ & \multirow[t]{4}{*}{0.090} \\
\hline & Grade II & 60 & $41.7 \%$ & 79 & $40.7 \%$ & 446 & $41.4 \%$ & \\
\hline & Grade III & 48 & $33.3 \%$ & 46 & $23.7 \%$ & 345 & $32.0 \%$ & \\
\hline & Unknown & 21 & $14.6 \%$ & 31 & $16.0 \%$ & 141 & $13.1 \%$ & \\
\hline \multirow[t]{3}{*}{ HER2 status } & Positive & 29 & $20.6 \%$ & 33 & $18.1 \%$ & 171 & $16.1 \%$ & \multirow[t]{3}{*}{0.393} \\
\hline & Negative & 112 & $79.4 \%$ & 146 & $80.2 \%$ & 877 & $82.4 \%$ & \\
\hline & Unclear & 0 & $0.0 \%$ & 3 & $1.6 \%$ & 16 & $1.5 \%$ & \\
\hline \multirow[t]{3}{*}{ Hormone receptor status } & Positive & 99 & $68.8 \%$ & 127 & $68.6 \%$ & 654 & $61.1 \%$ & \multirow[t]{3}{*}{0.053} \\
\hline & Mixed & 15 & $10.4 \%$ & 28 & $15.1 \%$ & 201 & $18.8 \%$ & \\
\hline & Negative & 30 & $20.8 \%$ & 30 & $16.2 \%$ & 215 & $20.1 \%$ & \\
\hline \multirow[t]{2}{*}{ ER status $^{\mathrm{a}}$} & Negative & 31 & $21.5 \%$ & 31 & $16.8 \%$ & 221 & $20.7 \%$ & \multirow[t]{2}{*}{0.438} \\
\hline & Positive & 113 & $78.5 \%$ & 154 & $83.2 \%$ & 849 & $79.3 \%$ & \\
\hline \multirow[t]{2}{*}{ PR status ${ }^{a}$} & Negative & 44 & $30.6 \%$ & 57 & $30.8 \%$ & 410 & $38.3 \%$ & \multirow[t]{2}{*}{0.043} \\
\hline & Positive & 100 & $69.4 \%$ & 128 & $69.2 \%$ & 660 & $61.7 \%$ & \\
\hline \multirow[t]{2}{*}{ Multifocality } & No & 91 & $63.2 \%$ & 129 & $69.7 \%$ & 745 & $69.6 \%$ & \multirow[t]{2}{*}{0.447} \\
\hline & Yes & 52 & $36.1 \%$ & 56 & $30.3 \%$ & 318 & $29.7 \%$ & \\
\hline \multirow[t]{3}{*}{ Lymph node status } & No & 61 & $42.4 \%$ & 132 & $68.0 \%$ & 491 & $45.6 \%$ & $<0.001$ \\
\hline & $\mathrm{N}+$ & 83 & $57.6 \%$ & 58 & $29.9 \%$ & 552 & $51.3 \%$ & \\
\hline & Missing & 0 & $0.0 \%$ & 4 & $2.1 \%$ & 34 & $3.2 \%$ & \\
\hline Follow-up characteristics & & & & & & & & \\
\hline $\begin{array}{l}\text { Mean time to recurrence } \\
\text { (in days) }\end{array}$ & Mean (SD) & 1070 & 428 & 1012 & 466 & 884 & 447 & $\underline{\mathrm{n} / \mathrm{a}}$ \\
\hline Type of recurrence & Local & 4 & 2.7 & 4 & 2.2 & 40 & 1.5 & $\mathrm{n} / \mathrm{a}$ \\
\hline & Regional & 4 & 2.7 & 3 & 1.6 & 57 & 2.1 & \\
\hline & Metastasis & 10 & 6.8 & 7 & 3.8 & 196 & 7.1 & \\
\hline Treatment characteristics & & & & & & & & \\
\hline Chemotherapy & Yes & 120 & $83.3 \%$ & 120 & $61.9 \%$ & 522 & $48.5 \%$ & $<0.001$ \\
\hline & Neoadjuvant & 94 & $78.3 \%$ & 89 & $74.2 \%$ & 390 & $74.7 \%$ & 0.758 \\
\hline & Adjuvant & 23 & $19.2 \%$ & 27 & $22.5 \%$ & 122 & $23.4 \%$ & \\
\hline & Both & 3 & $2.5 \%$ & 4 & $3.3 \%$ & 10 & $1.9 \%$ & \\
\hline Endocrine therapy & Yes & 102 & $70.8 \%$ & 121 & $62.4 \%$ & 707 & $65.6 \%$ & 0.267 \\
\hline
\end{tabular}


Table 1 (continued)

\begin{tabular}{|c|c|c|c|c|c|c|c|c|}
\hline & & $\operatorname{DBR}(n=144)$ & $\%$ & $\operatorname{IBR}(n=194)$ & $\%$ & MAS $(n=1077)$ & $\%$ & $p^{*}$ \\
\hline \multirow[t]{3}{*}{ Radiotherapy } & Yes & 52 & $36.1 \%$ & 28 & $14.5 \%$ & 359 & $33.3 \%$ & $<0.001$ \\
\hline & Before BR & 48 & $92.0 \%$ & 0 & $0.0 \%$ & $\mathrm{n} / \mathrm{a}$ & $\mathrm{n} / \mathrm{a}$ & $<0.001$ \\
\hline & After BR & 4 & $8.0 \%$ & 28 & $100.0 \%$ & $\mathrm{n} / \mathrm{a}$ & $\mathrm{n} / \mathrm{a}$ & \\
\hline \multicolumn{9}{|l|}{ Hospital characteristics } \\
\hline \multirow{3}{*}{$\begin{array}{l}\text { Hospital type (hospital of } \\
\text { oncologic treatment) }{ }^{\mathrm{b}}\end{array}$} & General hospital & 60 & $41.7 \%$ & 56 & $28.9 \%$ & 385 & $35.7 \%$ & $<0.001$ \\
\hline & Teaching hospital & 76 & $52.8 \%$ & 111 & $57.2 \%$ & 631 & $58.6 \%$ & \\
\hline & Academic hospital & 8 & $5.6 \%$ & 27 & $13.9 \%$ & 61 & $5.7 \%$ & \\
\hline \multirow{3}{*}{$\begin{array}{l}\text { Hospital type (hospital of } \\
\text { breast reconstruction) }^{\mathrm{b}}\end{array}$} & General hospital & 43 & $30.4 \%$ & 55 & $28.4 \%$ & $\mathrm{n} / \mathrm{a}$ & $\mathrm{n} / \mathrm{a}$ & 0.796 \\
\hline & Teaching hospital & 81 & $58.0 \%$ & 112 & $57.7 \%$ & $\mathrm{n} / \mathrm{a}$ & $\mathrm{n} / \mathrm{a}$ & \\
\hline & Academic hospital & 16 & $11.6 \%$ & 27 & $13.9 \%$ & $\mathrm{n} / \mathrm{a}$ & $\mathrm{n} / \mathrm{a}$ & \\
\hline \multirow{3}{*}{$\begin{array}{l}\text { Hospital volume (hospital } \\
\text { of oncologic treatment) }\end{array}$} & Low & 50 & $34.7 \%$ & 48 & $24.7 \%$ & 380 & $35.3 \%$ & 0.006 \\
\hline & Middle & 46 & $31.9 \%$ & 60 & $30.9 \%$ & 361 & $33.5 \%$ & \\
\hline & High & 48 & $33.3 \%$ & 86 & $44.3 \%$ & 336 & $31.2 \%$ & \\
\hline
\end{tabular}

DBR, mastectomy with delayed breast reconstruction; IBR, mastectomy with immediate breast reconstruction; MAS, mastectomy alone

${ }^{*}$ Chi-square tested

${ }^{\text {a }}$ Only available if hormone receptor status was tested

${ }^{\mathrm{b}}$ Hospitals were categorized as either general, teaching, or academic hospitals. Cancer-specialized centers were included in the category of academic hospitals

${ }^{c}$ Number of surgical treated non-metastatic breast cancer patients in 2012, categorized as low $(\leq 175)$, medium $(175<245)$, and high $(>=245)$ volume

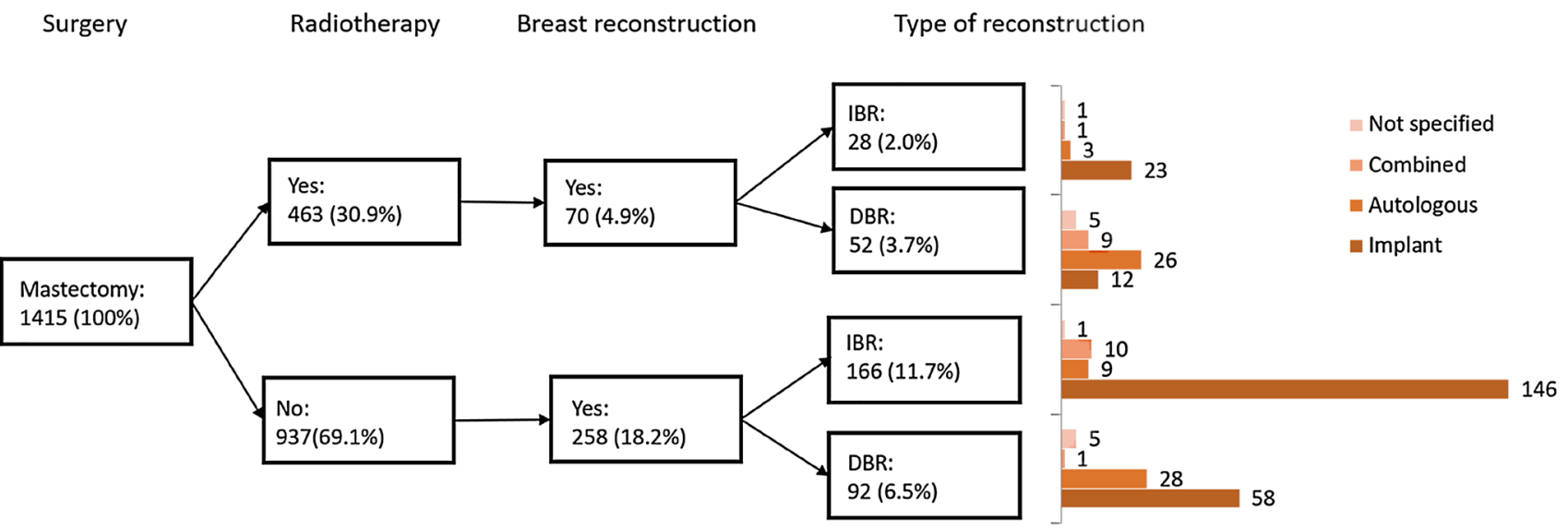

Fig. 1 Treatment characteristics for surgical treated patients diagnosed between January and March 2012. IBR, mastectomy with immediate breast reconstruction; DBR, mastectomy with delayed breast reconstruction. Percentages compared to population of patients treated with mastectomy $(n=1415)$. Absolute numbers of type of reconstruction are reported at the end of the corresponding bar time, starting $\geq 1$ year following mastectomy $(p=0.019)$. Patients treated with radiotherapy received DBR approximately 1 year later than patients without radiotherapy, with a mean time between diagnosis and DBR of 2.9 years (SD
1.26) versus 2.1 years (SD 1.23), respectively ( $p=0.002$; results not shown in Fig. 2).

In the multivariable Cox regression analyses, DBR was significantly associated with age $<35$ years (HR 2.22, CI 
Table 2 Type of breast reconstruction performed (n,\%) for patients diagnosed between January and March 2012

\begin{tabular}{llllll}
\hline & DBR $(n=144)$ & $\%$ & IBR $(n=194)$ & $\%$ & $p^{*}$ \\
\hline Autologous & 54 & $37.5 \%$ & 12 & $6.2 \%$ & $<_{\mathbf{0 . 0 0 1}^{\mathbf{b}}}$ \\
$\begin{array}{l}\text { Combined autologous } \\
\text { and implants }\end{array}$ & 10 & $6.9 \%$ & 11 & $5.7 \%$ & \\
Implants & & & & & \\
Not specified & 10 & $48.6 \%$ & 169 & $1.0 \%$ & \\
\hline
\end{tabular}

DBR, mastectomy with delayed breast reconstruction; IBR, mastectomy with immediate breast reconstruction

*Chi-square tested
$1.12-4.39, \mathrm{p}=0.024)$, and a high hospital volume (HR 1.87, CI 1.07-3.26, $\mathrm{p}=0.028$ ) (Table 4).

\section{Discussion}

The objective of the current study was to investigate the breast cancer patient population opting for DBR in the Netherlands. Based on one-quarter of newly diagnosed patients treated with mastectomy in 2012, DBR was performed in $10.2 \%(144 / 1,415)$ of patients, which is consistent with DBR rates of $9.3-13 \%$ from European literature (Denmark, the UK; 1999-2009) [30, 31]. Breast cancer patients with DBR significantly differed from patients with IBR or mastectomy alone. DBR patients were significantly younger, were more often diagnosed with stage II breast cancer and axillary lymph node metastases and were more often treated with chemotherapy or radiotherapy. This corresponds with the rationale that patients who are considered eligible for IBR are generally diagnosed with stage I breast cancer, with a good prognosis and a negative sentinel lymph node without the indication for axillary lymphadenectomy or radiotherapy [32]. In addition, the minority of DBR and mastectomy alone patients were treated at an academic hospital, unlike IBR in which the majority was treated in teaching hospitals or academic hospitals. This corroborates with available literature, demonstrating that (immediate) breast reconstruction rates were most probably higher in breast cancer specialized centers and hospitals with a high clinical breast surgery volume, because of high referrals to plastic surgeons [19, 24, 33].

Although not exclusively explaining the use of DBR, age below 50 years and treatment with (neoadjuvant) chemotherapy were significantly associated with DBR. This is in contrast to current literature. Initiation of adjuvant chemotherapy is recommended within 6-12 weeks after mastectomy [10, 34-36], and a recent large Dutch population-based study found that IBR did not reduce the likelihood of receiving adjuvant chemotherapy within 9 or 12 weeks following mastectomy [37]. This suggests that IBR does not delay the initiation of adjuvant chemotherapy to a clinically relevant extent [37], and thus DBR is not per se preferred over IBR if chemotherapy is indicated. Furthermore, literature has shown younger age is mainly related to higher IBR-rates [24, 38, 39], not to higher DBR-rates, and IBR-rates decrease significantly with increasing age [40]. Therefore, both associations may seem unexpected. However, our results could be explained by the following:

One could argue that the decision for DBR is not completely isolated. First, the decisions for IBR and DBR are interdependent, or as mentioned in our introduction section, part of a continuum of decisions. There are several reasons to prefer IBR over DBR, including cosmetic result and organizational benefits $[8,10,23]$. Patients who prefer a reconstruction but have a contra-indication for IBR, will most likely opt for DBR as a second best solution. However, risk-factors for surgical and medical complications as smoking, BMI $>30 \mathrm{~kg} / \mathrm{m} 2$, older age and co-morbidities (i.e. diabetes mellitus, hypertension), can negatively affect the outcomes of both IBR and DBR [10,13]. This is different for radiotherapy, which is considered as a relative contraindication for IBR in particular. The Dutch breast reconstruction guideline states it is preferable not to perform IBR with an implant if there is a high likelihood of postmastectomy radiotherapy [10]. The decision for DBR is, therefore, conditional to the decision regarding IBR, which may explain why we found no significant association of radiotherapy with DBR. This is illustrated by our sensitivity analysis. Radiotherapy was strongly and negatively associated with receiving any breast reconstruction (IBR or DBR) in contrast to mastectomy alone (Table 3). Radiotherapy has been reported as the most common reason to delay breast reconstruction until the acute side-effects of radiotherapy have been resolved, preferring DBR over IBR [10, 16, 18, 32]. Our Cox regression analysis demonstrated that the time between mastectomy and DBR was longer when radiotherapy was given (although just not significant); most patients were scheduled for DBR at least 2 years after radiotherapy completion.

The same may apply for age. Of all patients with a contraindication for IBR, young patients may still opt for DBR, whereas older patients may be satisfied with mastectomy alone. This is partly explained by both patients' preferences and clinicians' beliefs. As older patients are more likely to 
Table 3 Multivariable logistic regression for the odds of immediate or delayed breast reconstruction $(\mathrm{n}=338)$ versus mastectomy alone $(\mathrm{n}=1,077)$

\begin{tabular}{|c|c|c|c|c|c|c|}
\hline & & \multirow[t]{2}{*}{ Total $N=1.077$} & \multirow[t]{2}{*}{$\mathrm{BR} N=338$} & \multicolumn{2}{|c|}{ Multivariable } & \multirow[t]{2}{*}{$p^{*}$} \\
\hline & & & & OR & $95 \% \mathrm{CI}$ & \\
\hline \multicolumn{7}{|l|}{ Patient characteristics } \\
\hline \multirow[t]{4}{*}{ Age } & $<35$ & 46 & 30 & 14.74 & $7.42-29.26$ & $<0.001$ \\
\hline & $35-49$ & 323 & 155 & 4.33 & $3.18-5.89$ & $<0.001$ \\
\hline & $50-75$ & 757 & 150 & Ref & & \\
\hline & $75+$ & 289 & 3 & 0.06 & $0.02-0.20$ & $<0.001$ \\
\hline \multicolumn{7}{|l|}{ Tumor characteristics } \\
\hline \multirow[t]{6}{*}{ Clinical tumor-stage } & cT0 & 4 & 2 & 8.78 & $0.55-140.64$ & 0.125 \\
\hline & $\mathrm{cT} 1$ & 558 & 157 & Ref & & \\
\hline & $\mathrm{cT} 2$ & 600 & 127 & 0.91 & $0.67-1.24$ & 0.540 \\
\hline & cT3 & 127 & 29 & 1.41 & $0.79-2.53$ & 0.250 \\
\hline & $\mathrm{cT} 4$ & 57 & 2 & 0.24 & $0.05-1.24$ & 0.089 \\
\hline & Missing & 69 & 21 & 1.64 & $0.91-2.99$ & 0.103 \\
\hline \multirow[t]{4}{*}{ Grade } & Grade I & 198 & 53 & ref & & \\
\hline & Grade II & 585 & 139 & 0.98 & $0.66-1.46$ & 0.930 \\
\hline & Grade III & 439 & 94 & 0.77 & $0.49-1.20$ & 0.246 \\
\hline & Unknown & 193 & 52 & 0.98 & $0.53-1.79$ & 0.938 \\
\hline \multirow[t]{3}{*}{ Lymph node status } & No & 684 & 193 & ref & & \\
\hline & $\mathrm{N}+$ & 693 & 141 & 0.54 & $0.36-0.79$ & 0.002 \\
\hline & Not assessed/unknown & 38 & 4 & 0.17 & $0.04-0.69$ & 0.014 \\
\hline \multicolumn{7}{|l|}{ Treatment characteristics } \\
\hline \multirow[t]{3}{*}{ Chemotherapy } & No & 653 & 98 & Ref & & \\
\hline & Yes, adjuvant & 573 & 183 & 1.62 & $1.12-2.36$ & 0.011 \\
\hline & Yes, neoadjuvant & 172 & 50 & 2.25 & $1.21-4.20$ & 0.011 \\
\hline \multirow[t]{2}{*}{ Radiotherapy } & No & 976 & 258 & ref & & \\
\hline & Yes & 439 & 80 & 0.03 & $0.02-0.04$ & $<0.001$ \\
\hline \multirow[t]{2}{*}{ Endocrine therapy } & No & 485 & 115 & Ref & & \\
\hline & Yes & 930 & 223 & 1.02 & $0.75-1.40$ & 0.892 \\
\hline \multicolumn{7}{|l|}{ Hospital factors } \\
\hline \multirow[t]{3}{*}{ Hospital type oncologic treatment ${ }^{\mathrm{a}}$} & General hospital & 501 & 116 & ref & & \\
\hline & Teaching hospital & 818 & 187 & 0.68 & $0.47-0.99$ & 0.046 \\
\hline & Academic hospital & 96 & 35 & 1.85 & $1.11-3.09$ & 0.018 \\
\hline \multirow[t]{3}{*}{ Hospital volume $^{\mathrm{b}}$} & Low & 478 & 98 & ref & & \\
\hline & Middle & 467 & 106 & 1.64 & $1.12-2.42$ & 0.010 \\
\hline & high & 470 & 134 & 2.42 & $1.59-3.69$ & $<0.001$ \\
\hline Goodness-of-fit & Prob $>$ chi $2=0.98$ & & & & & \\
\hline Area under ROC curve & 0.89 & & & & & \\
\hline
\end{tabular}

BR, mastectomy with breast reconstruction (both immediate and delayed); cT, clinical tumor-stage; MDT, multidisciplinary team meeting *Chi-square tested

a Hospitals were categorized as either general, teaching, or academic hospitals. Cancer-specialized centers were included in the category of academic hospitals

b Number of surgical treated non-metastatic breast cancer patients in 2012, categorized as low $(\leq 175)$, medium $(175-245)$, or high $(>245)$ volume

have significant comorbidities, clinicians may find younger patients more eligible to undergo breast reconstruction [13, 40]. Moreover, one may speculate that older patients more easily accept the loss of their breast(s) or may not want to undergo major surgery. Younger patients in contrast may be more aware of breast reconstruction possibilities [24] and may be more assertive to discuss this option with their physician [23]. 
Fig. 2 Time (in years) between mastectomy and DBR per TNM-stage; cumulative number of DBR $(n=144)$. DBR, mastectomy with delayed breast reconstruction. Absolute cumulative numbers of patients with DBR are reported per year over each line

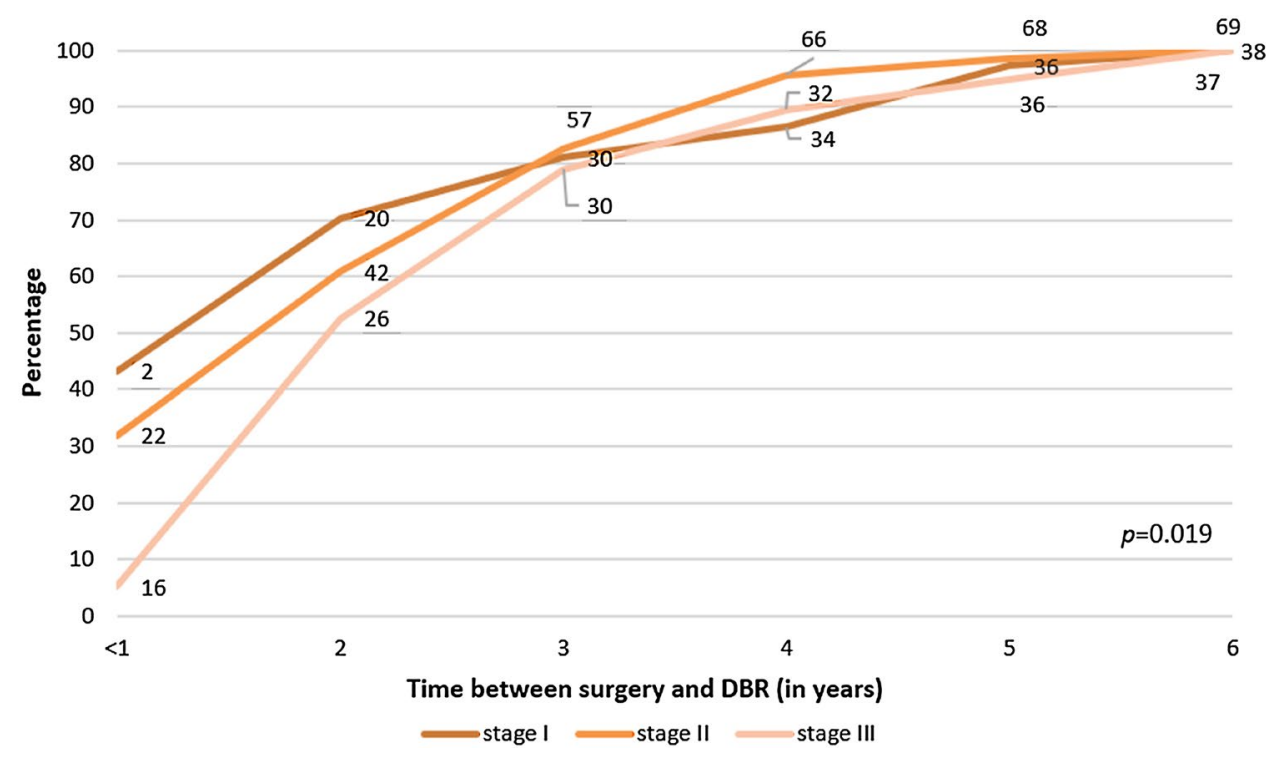

Second, treatment practice has changed since 2012. In the past, (neo)adjuvant therapies were considered contra-indications for IBR. Whether a reconstruction should be delayed if a patient requires radiotherapy remains a matter of debate. Chemotherapy, on the other hand, is no longer considered a major contraindication for IBR [41]. Results of a recent systematic review showed that neoadjuvant chemotherapy was not found to affect surgical complications as seroma, wound complications, skin or nipple necrosis, flap ischemia or loss, and implant loss [42]. In our cohort, DBR patients were more often treated with chemotherapy. Chemotherapy may be a proxy for disease severity and the prognosis of recurrence risk: DBR patients significantly more often had stage III disease and larger pre-treatment tumors. Therefore, reluctance towards IBR may have caused physicians to advice DBR instead. At that time, IBR was more cautiously offered to patients indicated for chemotherapy [43], while current evidence-based guidelines state chemotherapy is not a contra-indication for IBR [37, 41]. In our study we revealed a longer time between DBR in case of chemotherapy. The reason for this is not clear but could be patients were initially reluctant to undergo yet another stressful, and often mayor, surgical treatment, while still recovering from various significant physical complaints.

Implant-based breast reconstruction was the most frequently used technique (48.6\% DBR; $82.1 \%$ IBR) in our cohort. Nowadays, however, autologous reconstructions are increasingly recommended [10], as lower rates of total reconstruction failure and better long-term patient satisfaction with aesthetic outcome compared to implant reconstruction have been reported [6, 44, 45]. In our radiated subpopulation, the majority had received autologous breast reconstruction. The Dutch evidence-based guideline for breast reconstruction states that for DBR after radiotherapy it is preferable not to perform reconstruction with an implant only due to the high risk of implant loss [10], but rather add non-irradiated tissue to cover the implant or perform a full autologous reconstruction.

The nationwide and population-based character is a major strength of our study. However, the data obtained for this study were restricted to the time period from January to March 2012. Although this limits the size of our sample, our sample size calculation substantiates the number of included patients in our cohort. Because DBR is not routinely registered in the NCR, data had to be manually collected retrospectively over a time period of 5 years of follow-up. Still, within this quarter, patients who received DBR in a hospital different from were mastectomy was performed, may have been lost to follow-up. Patients may have decided independently for DBR at another hospital, leaving no paper trail at the hospital where the mastectomy was performed. These referral patterns are not easily identified by NCR's registrars, especially when time since diagnosis passes, probably resulting in a somewhat smaller number of identified DBR patients. However, in a study on IBR a 5\% hospital transfer was seen [46], which implies little incompleteness in our study. Active follow-up for all patients in the NCR is advisable.

Several latent variables may have accounted for the reduced explanatory power of our multivariable logistic regression model for the use of DBR. Factors as patients' preferences and psychological issues, behavior (smoking, BMI), comorbidities (morbidity obesity, diabetes mellitus), socioeconomic status, surgeons' beliefs and/or hospital organizational factors probably also affect the use of DBR, as they do in IBR [12, 19, 24], but are not collected in detail in the NCR. The lack of this information may have weakened our results and should be explored in 
Table 4 Cox regression for the time between mastectomy and delayed breast reconstruction

\begin{tabular}{|c|c|c|c|c|c|}
\hline & & \multirow[t]{2}{*}{$N=144$} & \multicolumn{2}{|c|}{ Multivariable } & \multirow[t]{2}{*}{$p^{*}$} \\
\hline & & & $\mathrm{HR}$ & $95 \% \mathrm{CI}$ & \\
\hline \multicolumn{6}{|l|}{ Patient characteristics } \\
\hline \multirow[t]{4}{*}{ Age } & $<35$ & 17 & 2.22 & $1.12-4.39$ & 0.024 \\
\hline & $35-49$ & 77 & 1.42 & $0.90-2.24$ & 0.136 \\
\hline & $50-75$ & 50 & ref & & \\
\hline & $75+$ & 0 & & omitted & \\
\hline \multicolumn{6}{|l|}{ Tumor characteristics } \\
\hline \multirow[t]{6}{*}{ Clinical tumor-stage } & cT0 & 0 & - & - & - \\
\hline & cT1 & 58 & Ref & & \\
\hline & $\mathrm{cT} 2$ & 58 & 0.79 & $0.51-1.22$ & 0.289 \\
\hline & cT3 & 19 & 1.07 & $0.53-2.13$ & 0.856 \\
\hline & cT4 & 2 & 1.50 & $0.30-7.55$ & 0.625 \\
\hline & missing & 7 & 1.65 & $0.70-3.91$ & 0.254 \\
\hline \multirow[t]{2}{*}{ Lymph node status } & No & 61 & Ref & & \\
\hline & $\mathrm{N}+$ & 83 & 0.86 & $0.53-1.37$ & 0.519 \\
\hline \multirow[t]{4}{*}{ Grade } & Grade I & 15 & ref & & \\
\hline & Grade II & 60 & 0.73 & $0.38-1.38$ & 0.331 \\
\hline & Grade III & 48 & 0.90 & $0.45-1.79$ & 0.770 \\
\hline & Unknown & 21 & 0.78 & $0.25-2.42$ & 0.673 \\
\hline \multicolumn{6}{|l|}{ Treatment characteristics } \\
\hline \multirow[t]{3}{*}{ Chemotherapy } & No & 24 & Ref & & \\
\hline & Yes, adjuvant & 94 & 0.54 & $0.29-1.01$ & 0.052 \\
\hline & Yes, neoadjuvant & 23 & 0.89 & $0.34-2.38$ & 0.822 \\
\hline \multirow[t]{2}{*}{ Radiotherapy } & No & 92 & Ref & & \\
\hline & Yes & 52 & 0.64 & $0.39-1.05$ & 0.080 \\
\hline \multirow[t]{2}{*}{ Endocrine therapy } & No & 42 & Ref & & \\
\hline & Yes & 102 & 0.84 & $0.54-1.32$ & 0.449 \\
\hline \multicolumn{6}{|l|}{ Hospital factors } \\
\hline \multirow{3}{*}{$\begin{array}{l}\text { Hospital type (hospital of } \\
\text { oncologic treatment) }\end{array}$} & General hospital & 60 & ref & & \\
\hline & Teaching hospital & 76 & 0.66 & $0.37-1.20$ & 0.172 \\
\hline & Academic hospital & 8 & 0.53 & $0.15-1.89$ & 0.329 \\
\hline \multirow{3}{*}{$\begin{array}{l}\text { Hospital type } \\
(\text { hospital of DBR })^{\mathrm{a}}\end{array}$} & General hospital & 43 & ref & & \\
\hline & Teaching hospital & 81 & 0.85 & $0.52-1.40$ & 0.520 \\
\hline & Academic hospital & 16 & 1.16 & $0.48-2.78$ & 0.739 \\
\hline \multirow{3}{*}{$\begin{array}{l}\text { Hospital volume (hospital } \\
\text { of oncologic treatment) }\end{array}$} & Low & 50 & ref & & \\
\hline & Middle & 46 & 1.02 & $0.63-1.67$ & 0.929 \\
\hline & High & 48 & 1.87 & $1.07-3.26$ & 0.028 \\
\hline
\end{tabular}

Prob $>$ chi $2=0.046$

cT, clinical tumor-stage

* Chi-square tested

${ }^{\text {a }}$ Hospitals were categorized as either general, teaching, or academic hospitals. Cancer-specialized centers were included in the category of academic hospitals

b Number of surgical treated non-metastatic breast cancer patients in 2012, categorized as low $(\leq 175)$, medium (175-245), or high ( $>245)$ volume future studies. For IBR patients, multiple hospital organizational factors were identified that could possibly also affect the use of DBR after mastectomy for stage I-III breast cancer in the Netherlands, including hospital type and volume, employment of a plastic surgeon, referral to a plastic surgeon, and the structural attendance of a plastic surgeon at the MDT [19].

The present study provides an overview of the use of DBR within a Dutch population of breast cancer patients treated with mastectomy in 2012, followed up till 5 years 
after diagnosis. Studies with long-term events since cancer treatment as primary outcome, such as recurrent disease, face the fact that clinical practice usually has changed over time since diagnosis because of improvements in cancer treatments. Similarly, this should be kept in mind when interpreting conclusions about DBR. Currently, BCT is considered at least equally safe as mastectomy [1], resulting in an increasing number of breast cancer patients treated with BCT [47]. However, the absolute number of DBR has also risen to 2,300 per year in 2019 (opendisdata, NABON Breast Cancer Audit). In addition, IBR-rates in mastectomy patients have increased over the past years as well. In 2019, 12,852 women were diagnosed with invasive breast cancer, of whom 4,252 patients were treated with a mastectomy [3]. Twenty-eight percent of these women received IBR, compared to only 16\% in 2012 (opendisdata, NABON Breast Cancer Audit). Regarding which type of breast reconstruction is used, recent concerns about the association between the use of breast implants and anaplastic large cell lymphoma (ALCL) [48] and its relatively high prevalence of 4.1 reported cases per million inhabitants in the Netherlands [49] could potentially further shift the preference to autologous reconstructions.

A population-based overview was given of mastectomy patients opting for DBR. Our study is a starting point for future practice evaluation. In order to answer aforementioned questions, data on DBR should be registered on regular basis similar to IBR, taking into account the fact that DBR can be performed until years after the mastectomy. Future research is needed to identify the trend of DBR within the Netherlands over the past years, the variation between hospitals in performing DBR after mastectomy, and the effects of patients' and surgeons' preferences, taking behavioral factors, comorbidities and socioeconomic status into account.

Acknowledgements The authors would like to thank the data-managers and staff of the Netherlands Cancer Registry for collecting the data used in this study.

Funding: Not applicable.

\section{Declarations}

Conflict of interest The authors declare no conflict of interest.

Ethical approval All procedures performed in studies involving human participants were in accordance with the ethical standards of the institutional and/or national research committee and with the 1964 Helsinki declaration and its later amendments or comparable ethical standards.

Informed consent This study was approved by the Privacy Review Board of the Netherlands Cancer Registry (NCR). Obtaining informed consent was not considered necessary.
Open Access This article is licensed under a Creative Commons Attribution 4.0 International License, which permits use, sharing, adaptation, distribution and reproduction in any medium or format, as long as you give appropriate credit to the original author(s) and the source, provide a link to the Creative Commons licence, and indicate if changes were made. The images or other third party material in this article are included in the article's Creative Commons licence, unless indicated otherwise in a credit line to the material. If material is not included in the article's Creative Commons licence and your intended use is not permitted by statutory regulation or exceeds the permitted use, you will need to obtain permission directly from the copyright holder. To view a copy of this licence, visit http://creativecommons.org/licenses/by/4.0/.

\section{References}

1. Lagendijk M, van Maaren MC, Saadatmand S, Strobbe LJA, Poortmans PMP, Koppert LB, Tilanus-Linthorst MMA, Siesling $\mathrm{S}$. Breast conserving therapy and mastectomy revisited: Breast cancer-specific survival and the influence of prognostic factors in 129,692 patients. Int J Cancer. 2018;142(1):165-75.

2. Cemal Y, Albornoz CR, Disa JJ, McCarthy CM, Mehrara BJ, Pusic AL, Cordeiro PG, Matros E: A paradigm shift in U.S. breast reconstruction: Part 2 . The influence of changing mastectomy patterns on reconstructive rate and method. Plast Reconstr Surg 2013, 131(3):320e-326e.

3. Audit NBC: NBCA Report 2019 In.; 2019.

4. Lagendijk M, van Egdom LSE, van Veen FEE, Vos EL, Mureau MAM, van Leeuwen N, Hazelzet JA, Lingsma HF, Koppert LB: Patient-Reported Outcome Measures May Add Value in Breast Cancer Surgery. Ann Surg Oncol 2018.

5. Howes BH, Watson DI, Xu C, Fosh B, Canepa M, Dean NR. Quality of life following total mastectomy with and without reconstruction versus breast-conserving surgery for breast cancer: A case-controlled cohort study. J Plast Reconstructive Aesthetic Sur : JPRAS. 2016;69(9):1184-91.

6. Kouwenberg CAE, de Ligt KM, Kranenburg LW, Rakhorst H, de Leeuw D, Siesling S, Busschbach JJ, Mureau MAM. Long-term health-related quality of life after four common surgical treatment options for breast cancer and the effect of complications: a retrospective patient-reported survey among 1871 patients. Plast Reconstr Surg. 2020;146(1):1-13.

7. Beugels J, Kool M, Hoekstra LT, Heuts EM, Tuinder SMH, van der Hulst R, Piatkowski A. Quality of life of patients after immediate or delayed autologous breast reconstruction: a multicenter study. Ann Plast Surg. 2018;81(5):523-7.

8. Cordeiro PG. Breast reconstruction after surgery for breast cancer. N Engl J Med. 2008;359(15):1590-601.

9. Metcalfe KA, Zhong T, Narod SA, Quan ML, Holloway C, Hofer S, Bagher S, Semple J. A prospective study of mastectomy patients with and without delayed breast reconstruction: long-term psychosocial functioning in the breast cancer survivorship period. J sur oncol. 2015;111(3):258-64.

10. Mureau MAM. Breast reconstruction guideline working G: Dutch breast reconstruction guideline. J Plast Reconstructive Aesthetic Surg: JPRAS. 2018;71(3):290-304.

11. Kronowitz SJ, Kuerer HM. Advances and surgical decisionmaking for breast reconstruction. Cancer. 2006;107(5):893-907.

12. Filipe MD, Siesling S, Vriens MR, van Diest PJ, Witkamp AJ, Mureau MAM: Socioeconomic status significantly contributes to the likelihood of immediate postmastectomy breast reconstruction in the Netherlands: A nationwide study. Eur J Surg Oncol 2020.

13. van Bommel ACM, Schreuder K, Veenstra RK, de Ligt KM, Vrancken Peeters M, Maduro JH, Siesling S, Mureau MAM. 
Discrepancies between surgical oncologists and plastic surgeons in patient information provision and personal opinions towards immediate breast reconstruction. Ann plast surg. 2018;81(4):383-8.

14. Lam TC, Hsieh F, J. B: The effects of postmastectomy adjuvant radiotherapy on immediate two-stage prosthetic breast reconstruction: a systematic review. Plast Reconstr Surg 2013, 132(3):511-518

15. Cordeiro PG, Albornoz CR, McCormick B, Hu Q, Van Zee $\mathrm{K}$. The impact of postmastectomy radiotherapy on two-stage implant breast reconstruction: an analysis of long-term surgical outcomes, aesthetic results, and satisfaction over 13 Years. Plast Reconstr Surg. 2014;134(4):588-95.

16. Javaid M, Song F, Leinster S, Dickson MG, James NK. Radiation effects on the cosmetic outcomes of immediate and delayed autologous breast reconstruction: an argument about timing. J Plast Reconstructive Aesthetic Surg : JPRAS. 2006;59(1):16-26.

17. Chen SA, Ogunleye T, Dhabbaan A, Huang EH, Losken A, Gabram S, Davis L, Torres MA. Impact of internal metallic ports in temporary tissue expanders on postmastectomy radiation dose distribution. Int J Radiat Oncol Biol Phys. 2013;85(3):630-5.

18. Ho AY, Hu ZI, Mehrara BJ, Wilkins EG. Radiotherapy in the setting of breast reconstruction: types, techniques, and timing. Lancet Oncol. 2017;18(12):e742-53.

19. Schreuder K, van Bommel ACM, de Ligt KM, Maduro JH, Vrancken Peeters M, Mureau MAM, Siesling S. Hospital organizational factors affect the use of immediate breast reconstruction after mastectomy for breast cancer in the Netherlands. Breast. 2017;34:96-102.

20. Alderman AK, Hawley ST, Morrow M, Salem B, Hamilton A, Graff JJ, Katz S. Receipt of delayed breast reconstruction after mastectomy: do women revisit the decision? Ann Surg Oncol. 2011;18(6):1748-56

21. Flitcroft K, Brennan M, Costa D, Wong A, Snook K, Spillane A. An evaluation of factors affecting preference for immediate, delayed or no breast reconstruction in women with high-risk breast cancer. Psychooncology. 2016;25(12):1463-9.

22. Ogrodnik A, MacLennan S, Weaver D, James T: Barriers to Completing Delayed Breast Reconstruction Following Mastectomy: a Critical Need for Patient and Clinician Education. Journal of cancer education : the official journal of the American Association for Cancer Education 2016.

23. de Ligt KM, van Egdom LSE, Koppert LB, Siesling S, van Til JA. Opportunities for personalised follow-up care among patients with breast cancer: a scoping review to identify preference-sensitive decisions. Eur J Cancer Care (Engl). 2019;28(3):13092.

24. van Bommel AC, Mureau MA, Schreuder K, van Dalen T, Vrancken Peeters MT, Schrieks M, Maduro JH, Siesling S. Large variation between hospitals in immediate breast reconstruction rates after mastectomy for breast cancer in the Netherlands. J Plast Reconstructive Aesthetic Surg: JPRAS. 2017;70(2):215-21.

25. van Bommel A, Spronk P, Mureau M, Siesling S, Smorenburg C, Tollenaar R, Vrancken Peeters MJ, van Dalen T. Breast-contourpreserving procedure as a multidisciplinary parameter of esthetic outcome in breast cancer treatment in The Netherlands. Ann Surg Oncol. 2019;26(6):1704-11

26. Albornoz CR, Bach PB, Pusic AL, McCarthy CM, Mehrara BJ, Disa JJ, Cordeiro PG, Matros E: The influence of sociodemographic factors and hospital characteristics on the method of breast reconstruction, including microsurgery: a U.S. population-based study. Plast Reconstr Surg 2012, 129(5):1071-1079.

27. Jeevan R, Mennie JC, Mohanna PN, O’Donoghue JM, Rainsbury $\mathrm{RM}$, Cromwell DA. National trends and regional variation in immediate breast reconstruction rates. Br J Surg. 2016;103(9):1147-56.

28. StataCorp L: Stata statistical software: Release 13. 2013.
29. Wilson Van Voorhis CR, Morgan BL: Understanding Power and Rules of Thumb for Determining Sample Sizes. Tutorials in Quantitative Methods for Psychology 2007, 3(2).

30. Hvilsom GB, Holmich LR, Frederiksen K, Steding-Jessen M, Friis $\mathrm{S}$, Dalton SO. Socioeconomic position and breast reconstruction in Danish women. Acta Oncol. 2011;50(2):265-73.

31. National Clinical Audit Support Programme (NCASP): National mastectomy and breast reconstruction audit (Report 2). In.: The Information Centre (NHS); 2009.

32. Filip CI, Jecan CR, Raducu L, Neagu TP, Florescu IP. Immediate versus delayed breast reconstruction for postmastectomy patients controversies and solutions. Chirurgia (Bucur). 2017;112(4):378-86.

33. Alderman AK, Hawley ST, Waljee J, Morrow M, Katz SJ. Correlates of referral practices of general surgeons to plastic surgeons for mastectomy reconstruction. Cancer. 2007;109(9):1715-20.

34. Senkus E, Kyriakides S, Ohno S, Penault-Llorca F, Poortmans P, Rutgers E, Zackrisson S, Cardoso F: Primary breast cancer: ESMO Clinical Practice Guidelines for diagnosis, treatment and follow-up. Ann Oncol 2015, 26(suppl_5):v8-v30.

35. Chavez-MacGregor M, Clarke CA, Lichtensztajn DY, Giordano SH Delayed initiation of adjuvant chemotherapy among patients with breast cancer. JAMA Oncol. 2016;2(3):322-9.

36. Federation of Medical Specialists: Breast Reconstruction Techniques After Mastectomy. In.; 2018.

37. Heeg E, Harmeling JX, Becherer BE, Marang-van de Mheen PJ, Vrancken Peeters M, Mureau MAM: Nationwide population-based study of the impact of immediate breast reconstruction after mastectomy on the timing of adjuvant chemotherapy. Br J Surg 2019.

38. Brennan ME, Spillane AJ. Uptake and predictors of post-mastectomy reconstruction in women with breast malignancy-systematic review. Eur J Surg Oncol. 2013;39(6):527-41.

39. Morrow M, Li Y, Alderman AK, Jagsi R, Hamilton AS, Graff JJ, Hawley ST, Katz SJ. Access to breast reconstruction after mastectomy and patient perspectives on reconstruction decision making. JAMA Surg. 2014;149(10):1015-21.

40. Kamali P, Curiel D, van Veldhuisen CL, Bucknor AEM, Lee BT, Rakhorst HA, Lin SJ. Trends in immediate breast reconstruction and early complication rates among older women: A big data analysis. J Surg Oncol. 2017;115(7):870-7.

41. Xavier Harmeling J, Kouwenberg CA, Bijlard E, Burger KN, Jager A, Mureau MA. The effect of immediate breast reconstruction on the timing of adjuvant chemotherapy: a systematic review. Breast Cancer Res Treat. 2015;153(2):241-51.

42. Lorentzen T, Heidemann LN, Möller S, Bille C: Impact of neoadjuvant chemotherapy on surgical complications in breast cancer: A systematic review and meta-analysis. Eur J Surg Oncol 2021.

43. Wanzel KR, Brown MH, Anastakis DJ, Regehr G. Reconstructive breast surgery: referring physician knowledge and learning needs. Plast Reconstr Surg. 2002;110(6):1441-50.

44. Yueh JH, Slavin SA, Adesiyun T, Nyame TT, Gautam S, Morris DJ, Tobias AM, Lee BT. Patient satisfaction in postmastectomy breast reconstruction: a comparative evaluation of DIEP, TRAM, latissimus flap, and implant techniques. Plast Reconstr Surg. 2010;125(6):1585-95.

45. Lagendijk M, van Egdom LSE, van Veen FEE, Vos EL, Mureau MAM, van Leeuwen N, Hazelzet JA, Lingsma HF, Koppert LB. Patient-reported outcome measures may add value in breast cancer surgery. Ann Surg Oncol. 2018;25(12):3563-71.

46. Heeg E, Schreuder K, Spronk PER, Oosterwijk JC. Marang-van de Mheen PJ, Siesling S, Peeters M, Audit NBC: Hospital transfer after a breast cancer diagnosis: A population-based study in the Netherlands of the extent, predictive characteristics and its impact on time to treatment. Eur J Surg Oncol. 2019;45(4):560-6.

47. van Maaren MC, Strobbe LJA, Koppert LB, Poortmans PMP, Siesling S. Nationwide population-based study of trends and regional 
variation in breast-conserving treatment for breast cancer. Br J Surg. 2018;105(13):1768-77.

48. de Boer M, van Leeuwen FE, Hauptmann M, Overbeek LIH, de Boer JP, Hijmering NJ, Sernee A, Klazen CAH, Lobbes MBI, van der Hulst R, et al. Breast implants and the risk of anaplastic largecell lymphoma in the breast. JAMA Oncol. 2018;4(3):335-41.

49. Stark B, Magnéli M, van Heijningen I, Parreira C, Bösch U, Rouif M, Halle M: Considerations on the Demography of BIA-ALCL in European Countries Based on an E(A)SAPS Survey. Aesthetic Plast Surg 2021.

Publisher's Note Springer Nature remains neutral with regard to jurisdictional claims in published maps and institutional affiliations. 